\title{
Boron Doped Diamond Thin Films on Large Area Ti6Al4V \\ Substrates for Electrochemical Application
}

\author{
Alessandra V. Diniz, ${ }^{\mathrm{a}, \mathrm{b} *}$, Neidenêi G. Ferreira ${ }^{\mathrm{a}}$, \\ Evaldo J. Corat ${ }^{\text {a }}$ Vladimir J. Trava-Airoldi ${ }^{\mathrm{a}}$ \\ anstituto Nacional de Pesquisas Espaciais, INPE, \\ Av. dos Astronautas, 1758, C.P. 515 12201-970, São José dos Campos - SP, Brazil \\ ' Instituto Tecnológico de Aeronáutica, ITA \\ São José dos Campos - SP, Brazil
}

Received: January 02, 2002; Revised: September 30, 2002

\begin{abstract}
Boron doped diamond thin films were grown on titanium alloy substrates (Ti6Al4V) with $36 \times 35 \times 1.3 \mathrm{~mm}$ at $873-933 \mathrm{~K}$ at $6.5 \times 10^{3} \mathrm{~Pa}$ during $8 \mathrm{~h}$ by hot filament $\mathrm{CVD}$ assisted technique. The boron source was obtained from a $\mathrm{H}_{2}$ line forced to pass through a bubbler containing $\mathrm{B}_{2} \mathrm{O}_{3}$ dissolved in methanol $(\mathrm{B} \backslash \mathrm{C}=6000 \mathrm{ppm})$. The films were grown on both sides of perforated and non-perforated substrates. Emphasis for diamond growing on perforated substrates have been done in order to increase the active surface area and hereafter to promote an easier electrolyte flow for wastewater treatment. The electrode performance was determined by cyclic voltammetry measurements in $\mathrm{KCl}, \mathrm{KNO}_{3}, \mathrm{Na}_{2} \mathrm{SO}_{4}, \mathrm{HCl}, \mathrm{HNO}_{3}$ and $\mathrm{H}_{2} \mathrm{SO}_{4}$ solutions and the reversibility behavior of the $\mathrm{Fe}(\mathrm{CN})_{6}^{3-1 / 4}$ at the Ti6Al4V/Diamond electrode were studied. Also, Scaning Electron Microcopy and Raman Scattering Spectroscopy were used for morphology and diamond quality evaluation, respectively.
\end{abstract}

Keywords: boron doped-diamond, Ti6Al4V, electrochemistry

\section{Introduction}

The evolution of semiconductor diamond research has shown promising results with doping process during CVD growth. The standard methods used for CVD boron doped diamond were initially thermal diffusion and ion implantation $^{1,2}$. These processes were made ex situ, after the film growth, and the no contamination of the growth reactor is the main advantage. However, alternative techniques have shown highly doped films, using in situ process from a solid source of boron inside of the reactor ${ }^{3}$ and by introducing of $\mathrm{B}_{2} \mathrm{O}_{3}$ in a methanol-acetone mixture ${ }^{4}$. It was observed better results evidenced by more homogeneity in films bulk, also showing films with a linear relation between the doping levels and boron concentration in the precursor source.

The diamond electrodes, which correspond to a typical p-type semiconductor, offer high sensitivity, good precision and high stability when compared with vitreous carbon, for example. Its more remarkable property is a wide working potential window concerning to hydrogen and oxygen evolution in aqueous solutions. Consequently, this kind of elec- trodes can withstand corrosive environments and favor alternative reactions ${ }^{5}$.

The main used substrate was the $\mathrm{Si}$ once its presents good characteristics for many applications. More recently, titanium alloy substrate became a good alternative for diamond growth since they have higher mechanical strength and electrical conductivity ${ }^{6}$. However some problems related to diamond film delamination became a goal to be overcome. It usually occurs due to the generation of high residual stresses in both films and substrate. Thermal stresses are often high in diamond films as a result of high deposition temperatures and the low thermal expansion coefficient of diamond compared to Ti6Al4 $\mathrm{V}^{7}$. Some solutions for this problem have been found, as the low deposition temperature and stress relieves by slow temperature dropping, and have been considered in this work. Also, an electrochemical investigation for characterization of boron-doped diamond electrodes on Ti6Al4V is one of the purposes of this work. We have carried out electrochemical experiments provid- 
ing voltammetric behavior studies for diamond electrodes in different neutral and acid solutions, and in $1 \mathrm{mM}$ of ferrocyanide at scan rates from 5 up to $500 \mathrm{mV} / \mathrm{s}$. The morphology and films quality were analyzed by SEM and Raman spectroscopy.

\section{Experimental Procedure}

Depositions were performed using a tubular stainless steel HFCVD reactor $100 \mathrm{~mm}$ diameter with one $\mathrm{H}_{2}$ line that passes through a bubbler containing $\mathrm{B}_{2} \mathrm{O}_{3}$ dissolved in methanol $(\mathrm{B} \backslash \mathrm{C}=6000 \mathrm{ppm}$ in solution, flux from the bubbler $=20 \mathrm{sccm})$, as has been described elsewhere ${ }^{8}$.

Ti6Al4V $35 \times 35 \times 1,3 \mathrm{~mm}$ perforated and non-perforated samples has been used. The laser made perforation increased geometric area by approximately $95 \%$.

All samples were ground using 600 and $1000 \mathrm{SiC}$ papers successively and polished using $9 \mathrm{~T}$ and $5 \mathrm{~T}_{2} \mathrm{O}_{2} \mathrm{O}_{3}$ powder, and then ultrasonically prepared in hexane bath with $0,25 \mu \mathrm{m}$ diamond powder for $1 \mathrm{~h}$.

The films were grown in both sides of the substrates with the aid of a tripod. The temperature and pressure were $900 \pm 25 \mathrm{~K}$ and $6.5 \times 10^{3} \mathrm{~Pa}$ respectively. The total gas flow was kept constant at $100 \mathrm{sccm}$ during $8 \mathrm{~h}$ with gas mixture of $1.0 \%$ vol. of methane in hydrogen, plus the $\mathrm{B}_{2} \mathrm{O}_{3}$ in methanol. The reactor has a rotative mechanism for the substrate that provides better uniformity during film growth. After the growth period the Ti6Al4V/diamond were cooled down to room temperature continually during $4 \mathrm{~h}$.

The non-perforated electrodes were assembled over a brass base and electrical contact was made with a silverbased paste to the rear side of the substrate. The group was isolated with silicone wax inside a Teflon box. The electrodes did not have surface pre-treatment before the electrochemical measurements.
Electrochemical activity of the diamond/Ti6Al4V and diamond/silicon electrodes was analyzed in $0.1 \mathrm{M}$ of neutral $\left(\mathrm{KCl}, \mathrm{Na}_{2} \mathrm{SO}_{4}\right.$ and $\left.\mathrm{NaNO}_{3}\right)$ and acidic $\left(\mathrm{HCl}, \mathrm{H}_{2} \mathrm{SO}_{4}\right.$ and $\mathrm{HNO}_{3}$ ) solutions. The anodic and cathodic charge was evaluated from cyclic voltammety in $1 \mathrm{mM}$ of ferrocyanide/ $0.1 \mathrm{M} \mathrm{KCl}$ at scan rates from 5 up to $500 \mathrm{mV} / \mathrm{s}$. The experiments were carried out at room temperature. The solution was exposed to air during electrochemical measurements. A conventional three-electrodes (work electrode, counter electrode and reference electrode), single-compartment electrochemical cell was used using a Microquímica potentiostat model MQPG-01. The solution was not stirred during the voltametry experiments. A reference electrode of $\mathrm{Ag} / \mathrm{AgCl}$ was used in this study. A platinum foil was also used during all the electrochemical measurements as counter electrode.

The characterizations of the films morphology and diamond quality were made by a LEO 440 scanning electron microscopy system and by a Renishaw Microscope 2000 micro-Raman scattering system, respectively.

\section{Results and Discussions}

\section{Scanning Electron Microscopy and Raman Spectroscopy}

First of all, surface and quality analyses have been carried out. SEM analysis for boron-doped diamond films on Ti6Al4V is depicted in Fig. 1. It is observed a polycrystalline film with predominant (111) and (100) orientation also determinated by X-Ray analysis. The films grew on the surface (Fig. 1a) and on the border of the samples, as is shown in Fig. 1b. The grains are very twinned, with average size around $1 \mu \mathrm{m}$ for $1.3 \mu \mathrm{m}$ film thickness, which was measured by SEM cross section. The thickness, the average grain size and the low growth rate are smaller in comparison with standard diamond electrodes on silicon ${ }^{9}$. This probably oc-
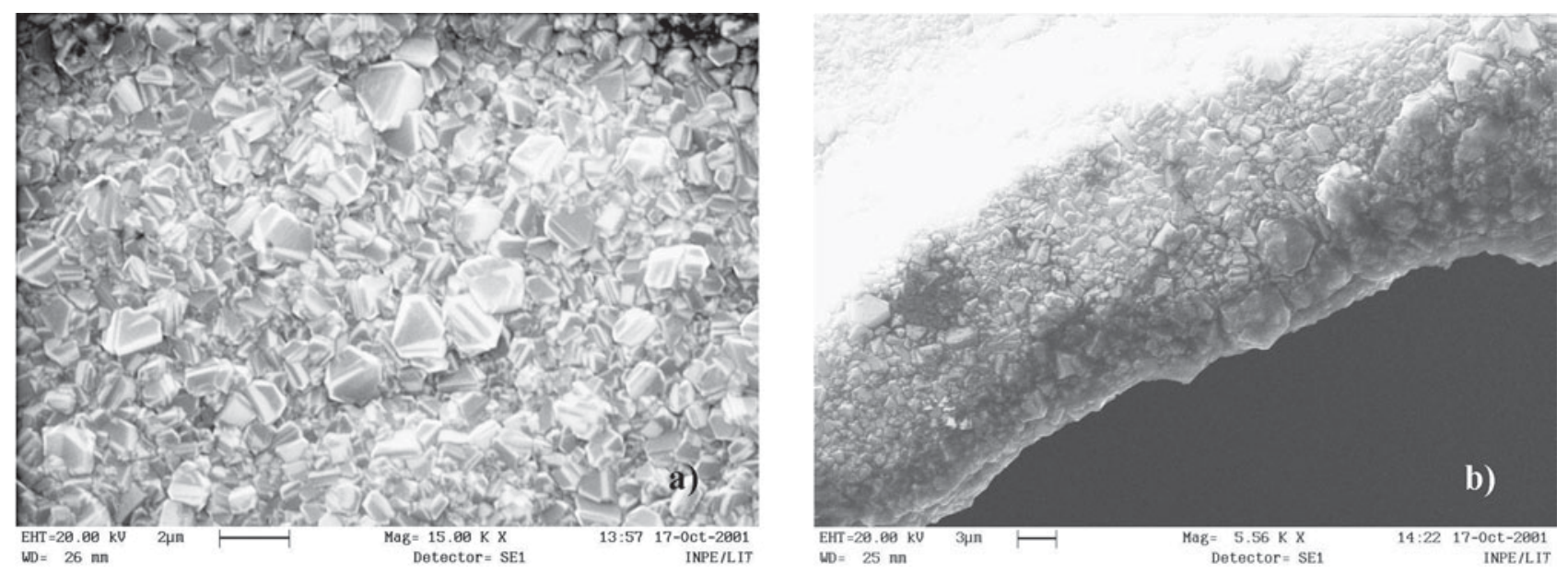

Figure 1. Scanning electron micrographs of boron-doped diamond film (a) superficial vision; (b) vision of the border of the sample. 
curred due to the low deposition temperature ${ }^{10}$ at $600{ }^{\circ} \mathrm{C}$. This temperature seems to be best for diamond growth on Ti6Al4V considering the best benefits in terms of diamond quality and thermal stress component value for keeping an adherent film ${ }^{11,12}$.

A TiC interlayer is formed between the diamond films and the Ti6Al4V as observed by X-Ray analysis. It is already know that at low temperature the titanium carbide interlayer has low growth rate and small thickness ${ }^{7}$. This characteristic favors the adhesion once the debonding occurs at the interface region between the $\mathrm{TiC}$ layer and the diamond film. Since the TiC formation is lower, the diamond formation is favored by available methane concentration in the gas phase, near the surface, and high nucleation rate is observed.

The Raman spectrum, as depicted in Fig. 2, shows a narrow $\mathrm{sp}^{3}$ peak at $1340 \mathrm{~cm}^{-1}$ and a wide band centered at $\sim 1550 \mathrm{~cm}^{-1}$. The displacement and the splitting of the diamond characteristic peak ( $1332 \mathrm{~cm}^{-1}$ for natural diamond) is attribute to the high residual stress in the film, which Terranova et al. ${ }^{13}$ also observed for diamond films on Ti6Al4V. This stress probably occurred due to the high mechanical resistance of the titanium alloys which could not allow a partial relaxation of the high thermal stress and the different compositions of the interfacial layers ${ }^{14}$. The

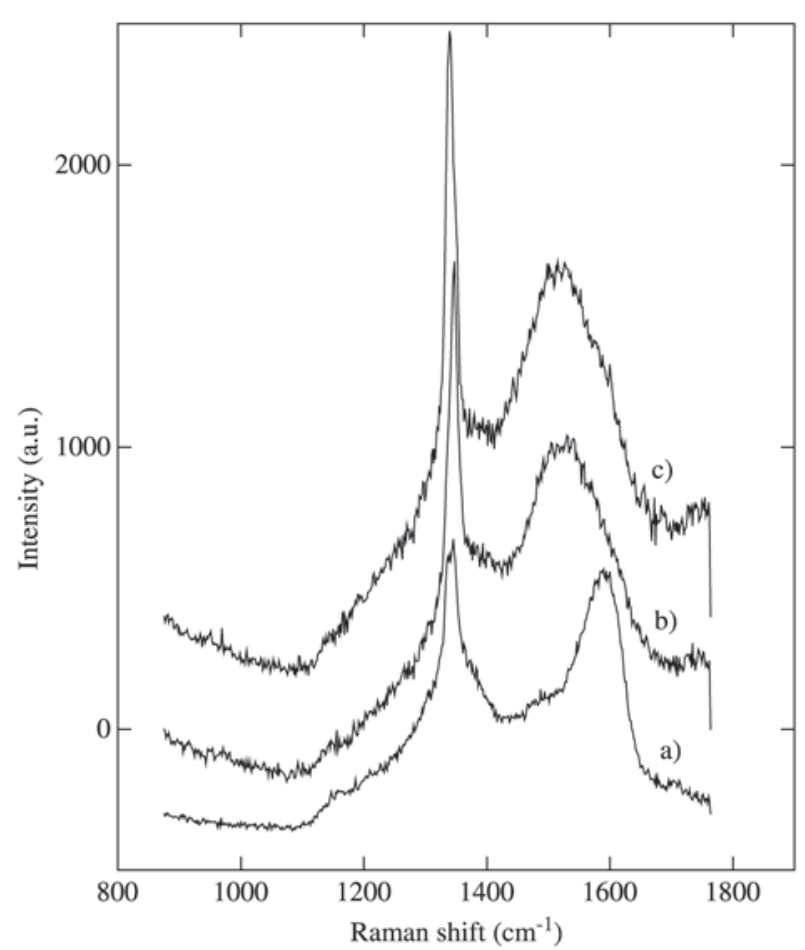

Figure 2. Raman spectra for boron-doped diamond in: a) non-perforated sample; b) between two holes on perforated sample; c) near to a hole on perforated sample. positive shifts have to be interpreted as films in compressive stress $^{15}$.

The wide band centered at $1550 \mathrm{~cm}^{-1}$ is attributed to $\mathrm{sp}^{2}$ carbons bond in the film ${ }^{16}$. This result was expected once the methane concentration around $2 \%$ is relatively higher than other values normally used ${ }^{17}$. As shown in Fig. 2a, this band is shifted, probably due to the small $\mathrm{D}$ band contribution ${ }^{15}$ and high amorphous carbon concentration in the film. This effect can also be explained the low $\mathrm{sp}^{3}$ characteristic peak intensity in this Raman spectrum.

Also, the Raman spectrum doesn't show a broad band centered at $1200 \mathrm{~cm}^{-1}$, that result of the breakdown of the $\mathrm{k}=0$ selection rule, probably because of the films are only slightly doped ${ }^{8,18,19}$.

\section{Electrochemical Behavior}

The electrochemical behavior has been studied in order to observe the potential window and other parameters concerning different active area. The electrochemical responses from non-perforated and perforated diamonds electrodes in $0,1 \mathrm{M} \mathrm{KCl}$ solution are shown in Fig. 3. All results are shown in terms of current density by using the geometric area of the samples.

The large potential window can be observed, as expected, for both electrodes. The anodic current density observed from the curve of perforated diamond is around twice higher than non-perforated diamond. This result is probably due to the difference between the real area and the geometric area, for both electrodes, which promote the double layer capacitance increase ${ }^{20}$.

In order to verify if the diamond/Ti6Al4V electrodes have the same electrochemical properties of the standard diamond $/$ silicon electrodes, the electrochemical activity at 2 and $-2 \mathrm{~V}$ of the two diamond/Ti6Al4V electrodes in acid

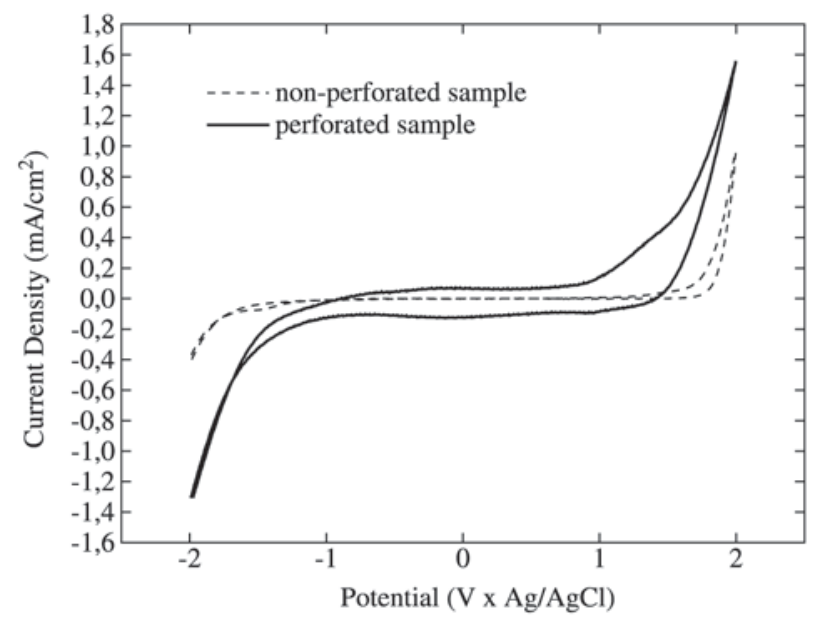

Figure 3. Cyclic voltametric behavior of the electrodes in $0,1 \mathrm{M}$ $\mathrm{KCl}$ solution at $\mathrm{v}=100 \mathrm{mV} / \mathrm{s}$. 
and neutral solutions were compared with diamond/silicon doped, as shown in Fig. 4 and 5, respectively ${ }^{20,21}$. The figures show the current densities values of the anodic $\left(\mathrm{I}_{\max }\right)$ and cathodic $\left(\mathrm{I}_{\text {min }}\right)$ reactions, which correspond to oxygen and hydrogen evolution. The values for all electrodes are in miliampere range indicating a coherent response of the electrodes. In the acid solution, the cathodic current density are approximately 10 times larger and anodic are similar to those in neutral solutions, confirming the high sensitivity of the diamond surface to hydrogen, in the form of $\mathrm{H}^{+}$ions, as observed by Deneuville et $a .^{21}$.

The main objective of the next experiments were to verify the electrode response agreement, using some criteria of reversibility ${ }^{22}$, for the redox reactions in $\mathrm{K}_{4} \mathrm{Fe}(\mathrm{CN})_{6}$ solution. The results obtained from cyclic voltammetry of $\mathrm{Fe}(\mathrm{CN})_{6}^{3-/ 4-}$ in $0,1 \mathrm{M} \mathrm{KCl}$ solution with perforated borondoped diamond/Ti6Al4V electrode and boron-doped diamond/Si are shown in Figs. 6-8. The data reported are corrected by IR compensation. The first criterion analyzed was

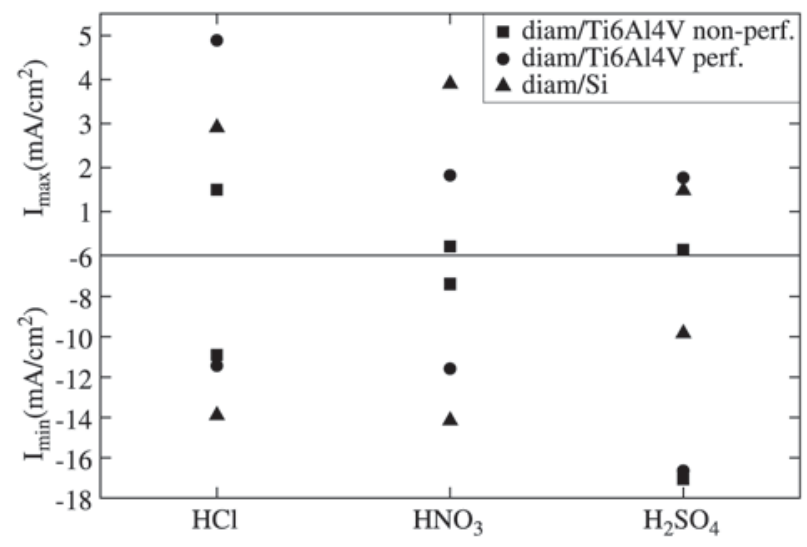

Figure 4. Current density in $0,1 \mathrm{M}$ acid solutions.

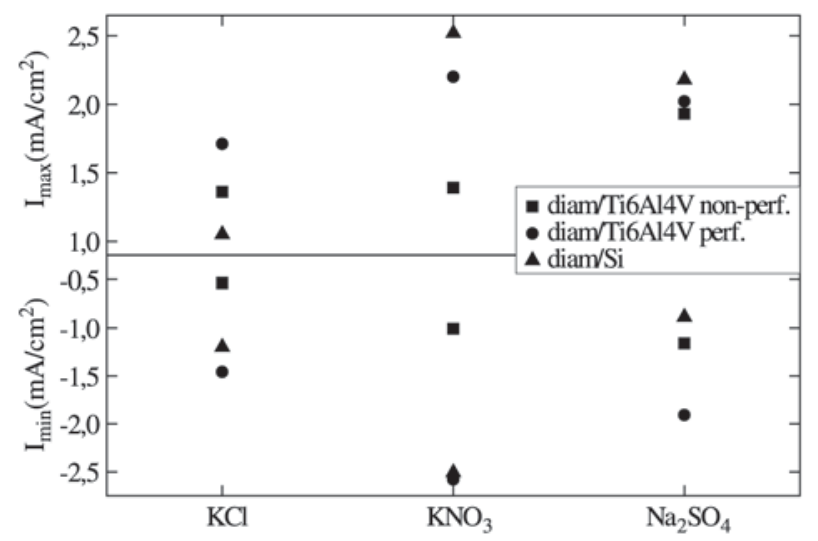

Figure 5. Current density in $0,1 \mathrm{M}$ neutral solutions. the relation between the cathodic peak current and the square root of the sweeping rate, which is shown in Fig. 6. The data indicate that the Ip increases with the relation sweep rate square in agreement. Other criterion was the separation between the anodic and cathodic peaks that in this case increases with the sweeping rate increase, as shown in Fig. 7. In addition, from Fig. 8, the cathodic peak potential changes to negatives values as a function of the sweeping rate increase. Therefore, all results indicated that $\mathrm{Fe}(\mathrm{CN})_{6}^{3-/ 4-} \mathrm{cou}-$ ple is quasi-reversible at diamond/Ti6Al4V, as at diamond $/ \mathrm{Si}^{23}$.

However one of the conditions to consider the reaction quasi-reversible is that $\Delta \mathrm{Ep}$ values tend to $60 \mathrm{mV}$ (once $\mathrm{n}$ is equal 1 in this system) at low sweeping rate. In our case, the higher values found for $\Delta \mathrm{E}_{\mathrm{p}}$, including at low sweep rates, and the original forms of the curves suggest that the films

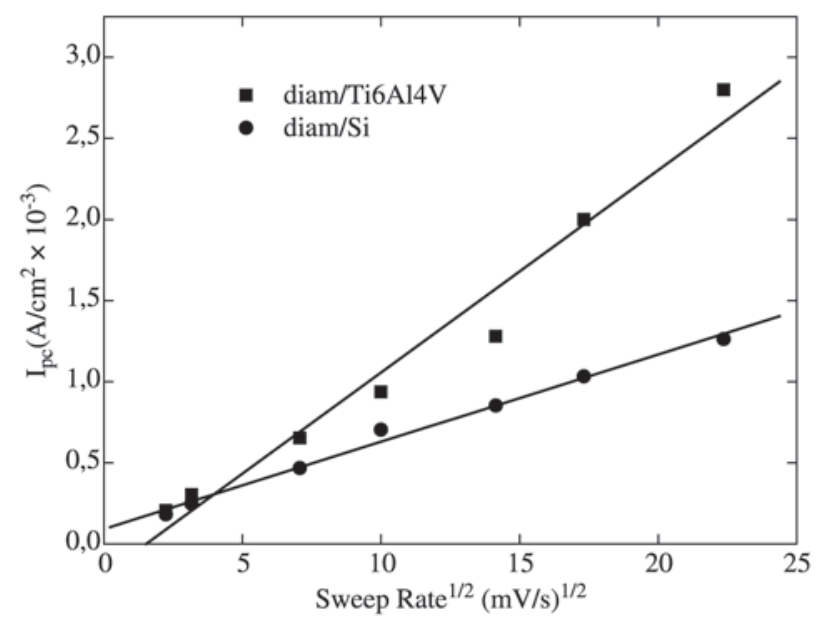

Figure 6. Cathodic peak current as a function of (sweep rate) $)^{1 / 2}$ in $1 \mathrm{mM}$ Ferrocyanide/0,1 M KCl for perforated electrode.

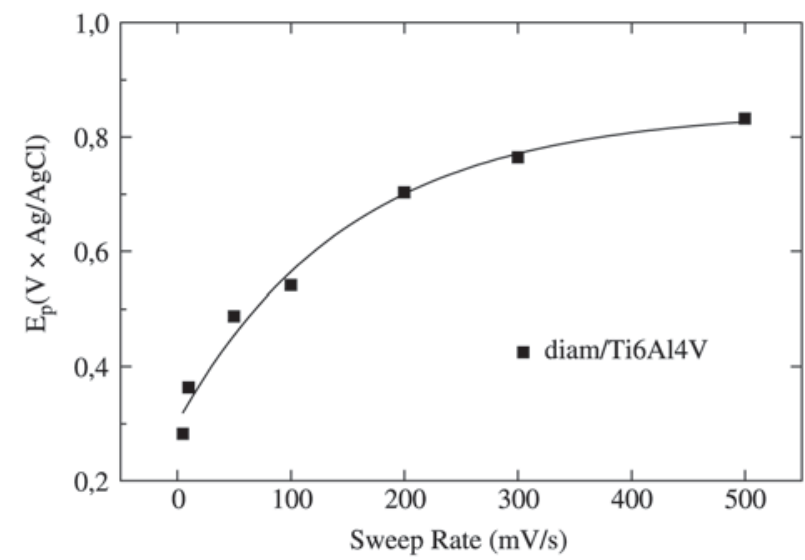

Figure 7. $\triangle \mathrm{Ep}$ as a function of sweep rate in $1 \mathrm{mM}$ Ferrocyanide $0,1 \mathrm{M} \mathrm{KCl}$ for perforated electrode. 


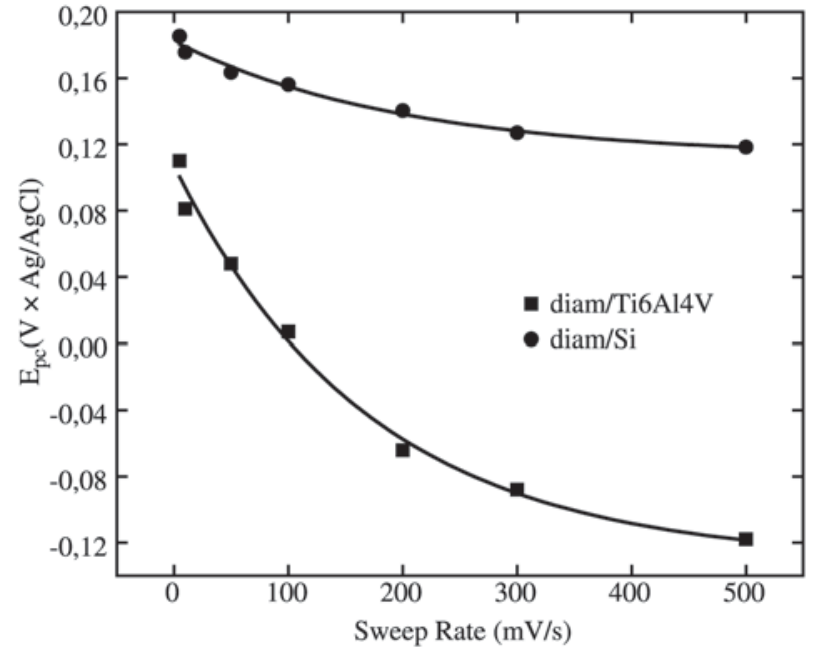

Figure 8. Cathodic potential as a function of sweep rate in $1 \mathrm{mM}$ Ferrocyanide/0,1 $\mathrm{M} \mathrm{KCl}$ for perforated electrode.

are more resistive or less doped, as described by Ramesham and $\operatorname{Rose}^{24}$.

\section{Conclusion}

The thin films of boron-doped diamond were grown on perforated and non-perforated Ti6Al4V samples with good adhesion. SEM and Raman Scattering Spectroscopy characterized their quality and morphology indicating films with small average grain size, highly stressed, slightly doped and with some quantity of $\mathrm{sp}^{2}$ carbon.

The electrodes electrochemical behavior showed similarity with the standard electrodes deposited on silicon. Although in the perforated samples the double layer capacitance was increased. This behavior turns them suitable for electrochemical capacitors applications. The electrochemical properties, as large potential window, electrochemical activity in different neutral and acid solutions and cyclic voltammetry behavior of the $\mathrm{Fe}(\mathrm{CN})_{6}^{3-14-}$ at the electrodes, were the expected ones. This is very important to assure good performance in future applications.

\section{Acknowledgements}

The authors are very grateful to FAPESP for financial support and to Mr. Jognes Panasiewicz Junior from Instituto Nacional de Pesquisas Espaciais for SEM analyses and Mrs. Maria Auxiliadora S. Oliveira from Instituto Tecnológico de Aeronáutica (ITA) for potentiostat equipment.

\section{References}

1. Tsai, W.; Delfino, M.; Ching, L.Y.; Reynolds, G.; Hodul, D.; Cooper, C.B New Diamond Science and Technology,
MRS Int. Conf. Proc. P. 937, 1991.

2. Prawer, S. Diamond and Related Material, v. 4, p. 862, 1995.

3. Martin, H.B.; Argotia, A.; Landau, U.; Anderson A.B.; Angus, J.C. J. Electrochem. Soc., v. 143, n. 6, p. 133, 1996.

4. Okano, K.; Akiba, Y.; Kurosu, T.; Lida, M.; Nakamura, T. J. Cristal Growth, v. 99, p. 1192, 1990.

5. Tenne, R.; Lévy-Clément, C. Israel Journal of Chemistry, v. 38, p. 57-73, 1998.

6. Fisher, V.; Gandini, D.; Laufer, S.; Blank, E.; Comninellis, C. Electrochimica Acta, v. 44, p. 521-524, 1998.

7. Peng, X.L.; Clyne, T.W. Thin Solid Films, v. 293, p. 264-269, 1997.

8. Silva, L.L.G.; Corat, E.J.; Barros, R.C.M.; Trava-Airoldi ,V.J.; Leite, N.F.; Iha, K. Materials Research, v. 2, n. 2, p. 99-103, 1999.

9. Ferreira, N. G.; Abramof, E.; Corat, E.J.; Leite, N.F.; Trava-Airoldi, V.J. Diamond and Related Materials, v. 10, p. 750-754, 2001.

10. Fan, W.D; Jagannadham, K.; Narayan, J. Surface and Coatings Tecnology, v. 91, p. 32-36, 1997.

11. Rats, D.; Vandenbulcke, L.; Serin, V.; Sevely, J. Thin Solid Films, v. 270, p. 177-183, 1995.

12. Vandenbulcke, L.; Rats, D.; Herbin, R. Materials Letters, v. 27, p. 77-80, 1996

13. Scardi, P.; Leoni, M.; Cappuccio, G.; Sessa, V.; Terranova, M.L. Diamond and Related Materials, v. 6, p. 807, 1997.

14. Perry, S.S.; Ager, J.W.; Somorjai, G.A. J. Appl. Phys, v. 74, p. 7542-7550, 1993.

15. Knight, D.S; White, W.B. J. Mater. Res, v. 4, n. 2, p. 385-393, 1989.

16. Nemanich, R.J.; Glass, J.T.; Lucovsky, G.; Shroder, R.E. J. Vac. Sci. Technol. A, v. 6, p. 1783-1787, 1988.

17. Gheeraert, E.; Deneuville, A.; Bonnot, A.M. Diamond and Related Materials, p. 525-528, 1992.

18. Wang, W.L.; Pólo, M.C.; Sanchez, G.; Esteve, J. J. Appl. Phys, v. 80, p. 1846-1850, 1996.

19. Liao, X.Z.; Zhang, R.J.; Lee, C.S.; Lee, S.T.; Lam, Y.W. Diamond and Related Materials, v. 6, p. 521-525, 1997.

20. Ferreira, N.G.; Silva, L.L.G.; Corat, E.J. Diamond Related Materials, v. 11, p. 657-661, 2002.

21. Lévy-Clément, C.; Zenia, F.; Ndao, N.A.; Deneuville, A. New Diamond and Frontier Carbon Technology, v. 9, n. 3, p.189-206, 1999.

22. Greef, R.; Peat, R.; Peter, L.M.; Pletcher, D.; Robinson, J. Instrumental Methods in Electrochemistry, John Wiley \& Sons, New York, cap. 3, 1985.

23. Ferreira, N.G.; Silva, L.L.G.; Corat, E.J. in press.

24. Ramesham, R.; Rose, M.F. Diamond Related Materials, v. 6, p. 17-27, 1997. 